Article

\title{
Influence of Multiple Openings on Reinforced Concrete Outrigger Walls in a Tall Building
}

\author{
Han-Soo Kim * (D, Yi-Tao Huang and Hui-Jing Jin \\ Department of Architecture, Konkuk University, Seoul 05029, Korea; icyhyt@konkuk.ac.kr (Y.-T.H.); \\ hg1827@daum.net (H.-J.J.) \\ * Correspondence: hskim@konkuk.ac.kr; Tel.: +82-2-2049-6110
}

Received: 1 October 2019; Accepted: 13 November 2019; Published: 15 November 2019

check for updates

Featured Application: The reinforced concrete outrigger wall with multiple openings can be used to replace the conventional steel outrigger trusses in tall building structures.

\begin{abstract}
Outrigger systems have been used to control the lateral displacement of tall buildings. Reinforced concrete (R.C.) outrigger walls with openings can be used to replace conventional steel outrigger trusses. In this paper, a structural model for an R.C. outrigger wall with multiple openings was proposed, and the effects of the multiple openings on the stiffness and strength of the outrigger walls were evaluated. The equivalent bending stiffness of the outrigger wall was derived to predict the lateral displacement at the top of tall buildings and internal shear force developed in the wall. The openings for the passageway in the wall were designed by the strut-and-tie model. The stiffness and strength of the outrigger wall with multiple openings was analyzed by the nonlinear finite element analysis. Taking into consideration the degradation in stiffness and strength, the ratio of the opening area to the outrigger wall area is recommended to be less than $20 \%$. The degradation of stiffness due to openings does not affect the structural performance of the outrigger system when the outrigger has already large stiffness as the case of reinforced concrete outrigger walls.
\end{abstract}

Keywords: outrigger wall; multiple openings; deep beam; stiffness; shear strength; tall building

\section{Introduction}

With the development of tall building structures, the outrigger system has become one of the most popular structural systems that control the lateral displacement of such buildings. Several researchers and engineers have been studying and developing the outrigger system because it performs well in controlling the lateral displacement at the top of a tall building by reducing the overturning moment [1]. For example, the Shanghai Tower, Hong Kong IFC2, and Taipei 101 are successful applications of the system in tall buildings [2]. Most of the previous research studies focused on the optimum location of outriggers and lateral stiffness of the whole structure. Taranath [3] assumed a rigid outrigger beam for single-outrigger structures, and proposed that the optimum location of an outrigger is 0.455 of the total height from the top. McNabb and Muvdi [4] proposed that the optimum locations for two outriggers are 0.312 and 0.685 of the total height from the top based on Taranath's research. Smith and Nwaka [5] presented generalized results for optimum locations in multi-outrigger structures by assuming rigid outriggers in flexure. Smith and Salim [6] proposed equations for the optimum locations of outriggers by considering their flexibility. Hoenderkamper and Bakker [7] considered the bending and racking shear stiffness of the outrigger truss to determine the optimum location of the outrigger. The research studies on outrigger-braced structures have been summarized and some further studies have been attempted by $\mathrm{Wu}$ and $\mathrm{Li}$ [8]. Recently, Kim et al. [9] proposed a dual-purpose outrigger system to reduce the lateral displacement and differential column shortening. 
Even though some researchers assumed equivalent beams for the outriggers to derive equations for the optimum locations, most of the outriggers built were made of steel trusses. Although there are a few applications of reinforced concrete outrigger walls, such as Chong Qing Raffles City [10], discussing the walls is not enough. Furthermore, too little attention has been paid to the reinforced concrete outrigger walls with openings.

In theory, the deeper the outrigger, the stiffer the structure [11]. It means that a deep outrigger, such as an outrigger wall, can provide more effective lateral load-resistance for high-rise structures. At the same time, reinforced concrete outrigger walls can be cost-effective systems because of the same construction procedure as reinforced concrete core walls. However, as large concrete structures, the reinforced concrete outrigger walls are heavy and space consuming. As a result, it is necessary to solve the problems associated with making better use of the space occupied by outrigger walls. In this study, a model for arranging multiple openings on reinforced concrete outrigger walls, as shown in Figure 1, is proposed. Moreover, the study investigates the influence of multiple openings on the stiffness and strength of the outrigger walls and whole tall building structure.

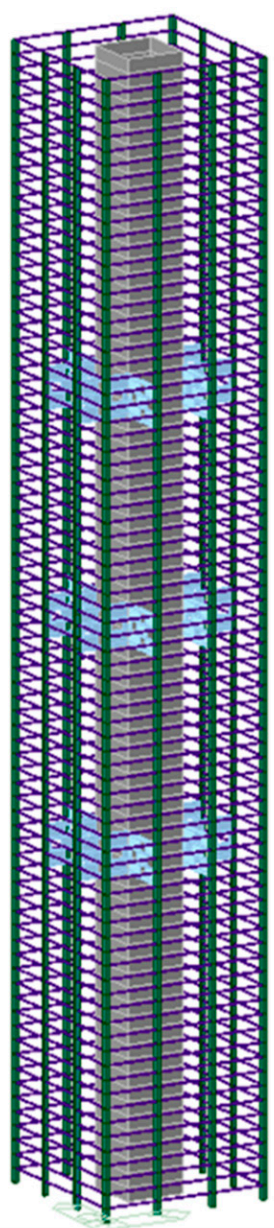

- Overall high-rise structure

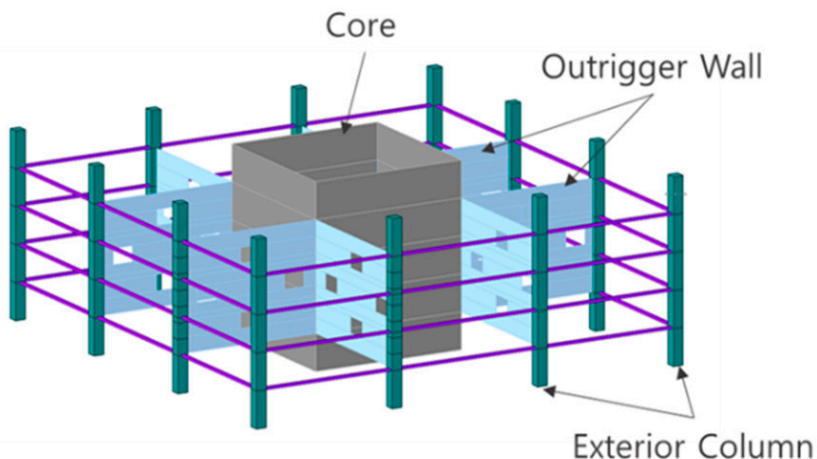

- Detail of outrigger level

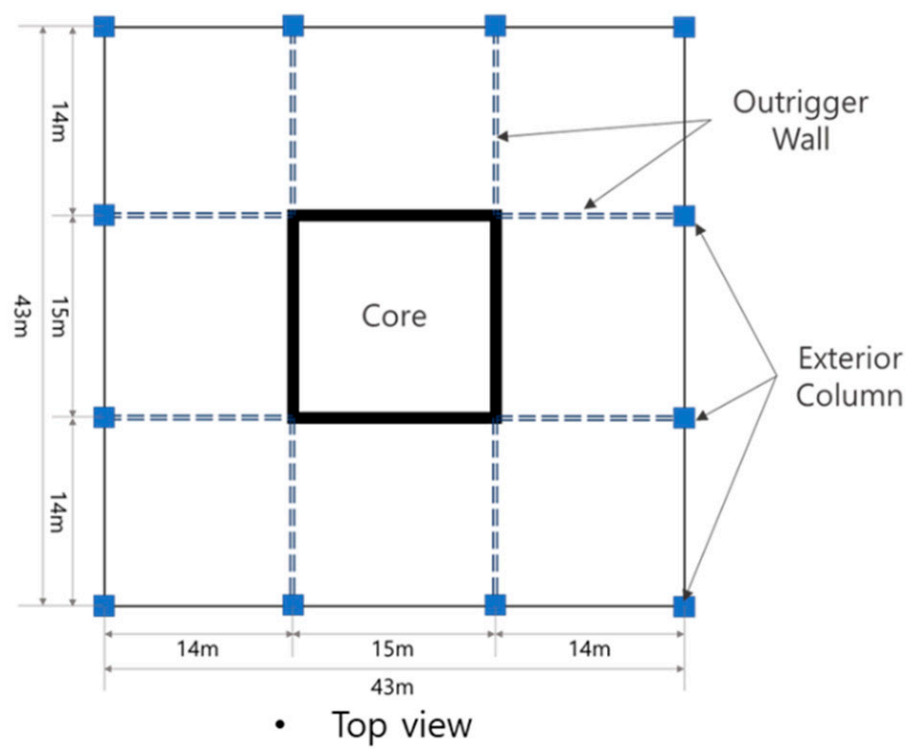

Figure 1. A typical tall building structure with reinforced concrete outriggers walls with multiple openings.

Given the aspect ratio of the outrigger walls, they can be designed as deep beams with openings. Kong and Sharpe [12] proposed a shear strength equation for deep reinforced concrete beams with web openings. Tan et al. [13] have predicted the capacity of deep beams with openings using the strut-and-tie model. Tang and Tan [14] paid more attention in the evaluation of the ultimate shear strength of deep beams, but there was only an opening in every shear region while the opening is 
placed in the critical load path. Although several studies have been performed on deep beams with web openings, there are still difficulties in predicting the structural behavior of deep beams with multiple openings. In this study, analytic equations used to predict the internal shear forces on outrigger walls due to the lateral loads are derived and the results are verified through numerical examples. After that, an outrigger wall with four openings was proposed through the strut-and-tie model. Subsequently, the linear and nonlinear finite element method and strut-and-tie model were used to evaluate the influence of the size of multiple openings on the stiffness and shear strength of reinforced concrete outrigger walls. The study ends up investigating the influence of multiple openings on the lateral displacement of whole tall building structures by using the proposed analytic equations.

\section{Design of Reinforced Concrete Outrigger Wall with Multiple Openings}

In this section, analytic equations used to predict the lateral displacement at the top of the building and shear forces developed in each outrigger wall are derived and verified with the result of finite element analysis. Subsequently, a structural model for the outrigger wall with four openings is proposed.

\subsection{Effect and Demand of Outrigger Walls}

The internal shear force of the outrigger walls due to lateral loads is derived based on the simplified model of the core wall and outrigger structural system [15]. A simplified model of tall building structures with multiple outriggers is shown in Figure 2. The core wall is connected to the perimeter columns through the outriggers. When lateral loads are applied at the central core wall, the outrigger develops axial forces in the perimeter columns. The limitation of the simplified model is that only flexural deformation of the outrigger is considered, and the length of the outrigger is assumed as the distance from the center of the core to that of the perimeter column. These assumptions are different from the actual behavior of outrigger walls. To enhance the accuracy of this simplified model, an equivalent bending stiffness $(E I)_{O}$ was proposed by considering the shear deformation of beams and the clear span of outrigger walls.
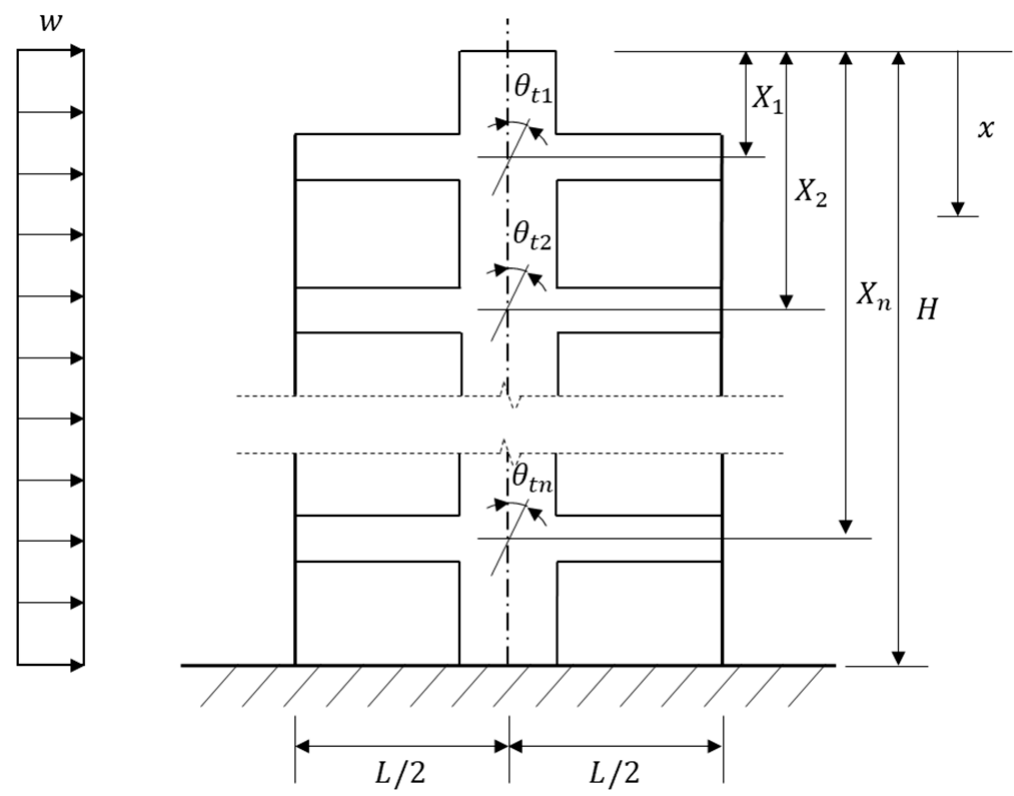

Figure 2. Simplified analysis model with multiple outriggers. The core wall is connected to the perimeter columns through the outriggers.

Because the outrigger walls belong to the category of deep beams [16], the total deformation is the sum of flexural and shear deformations, and the actual flexural distance is the clear span $l_{0}$, as shown 
in Figure 3. According to the principle of virtual works, for the outrigger wall with a moment of inertia $I_{0}$ and cross-sectional area $A_{0}$, the equivalent bending stiffness $(E I)_{0}$ can be obtained by the following equation.

$$
(E I)_{o}=\left(1+\frac{c}{2 l_{o}}\right)^{3} E I_{o} /\left(1+\frac{12 E I_{o}}{G \kappa_{s} A_{o} L^{2}}\right)
$$

where $E$ and $G$ are the modulus of elasticity and shear modulus, respectively. $\kappa_{s}$ is the shear coefficient to account for the shear deformation, which is 0.83 for a rectangular section. $c$ is the width of the core wall, and $L$ is the distance from the center of the core wall to the center of perimeter column, as shown in Figure 3.

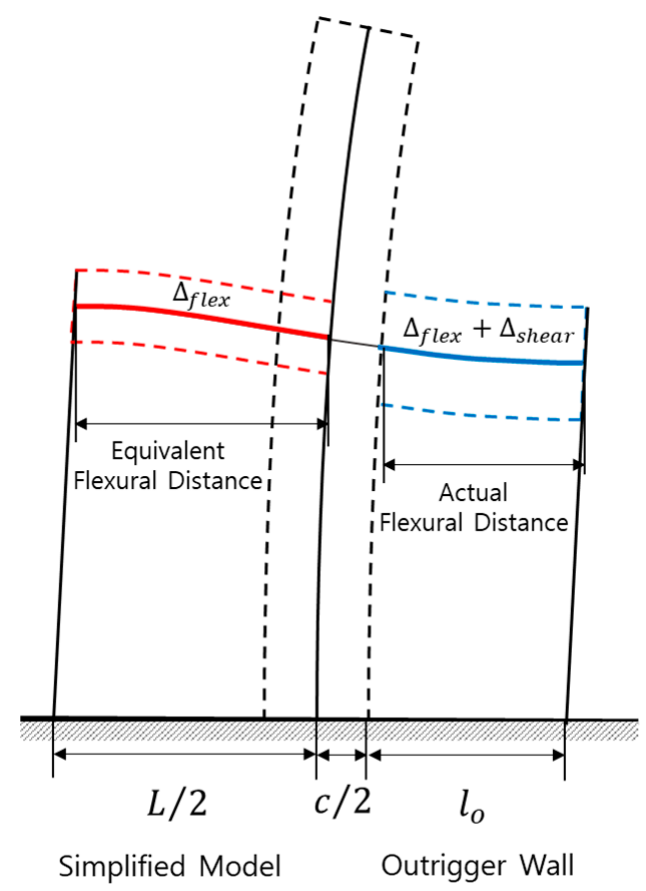

Figure 3. Shear and flexural deformations of the outrigger wall are considered and the clear span rather than center-to-center span is used in the equivalent bending stiffness of the outrigger wall.

For the core, the rotation $\theta_{t i}$ at the $i$ th outrigger level due to the lateral load $w$ and the restraining moment $M_{r i}$ can be given by the following equation.

$$
\theta_{t i}=\frac{1}{(E I)_{t}}\left[\int_{x_{1}}^{x_{2}}\left(\frac{w x^{2}}{2}-M_{r 1}\right) d x+\int_{x_{2}}^{x_{3}}\left(\frac{w x^{2}}{2}-M_{r 1}-M_{r 2}\right) d x+\ldots+\int_{x_{n}}^{H}\left(\frac{w x^{2}}{2}-M_{r 1}-\ldots-M_{r n}\right) d x\right]
$$

where $(E I)_{t}$ represents the bending stiffness of the core wall. At the same outrigger level, the rotation of the inboard end of the outrigger $\theta_{\text {oti }}$, where it attaches to the core, is due to the axial forces of perimeter columns and overturning moment $M_{r i}$. It was noted that the restraining moment for the core and overturning moment for the outrigger walls have the same value and opposite directions. Hence, $M_{r i}$ is used to represent both. The rotation $\theta_{\text {oti }}$ can be obtained by the following equation.

$$
\theta_{o t i}=\frac{2 M_{r 1}\left(H-X_{1}\right)}{L^{2}(E A)_{c}}+\frac{2 M_{r 2}\left(H-X_{2}\right)}{L^{2}(E A)_{c}}+\ldots+\frac{2 M_{r i}\left(H-X_{i}\right)}{L^{2}(E A)_{c}}+\frac{M_{r i} L}{12(E I)_{o i}}
$$

where $(E A)_{c}$ represents the axial stiffness of perimeter columns. 
Because of $\theta_{t i}=\theta_{o t i}$, the restraining moment $M_{r i}$ can be obtained in the following matrix form.

$$
\left[\begin{array}{c}
M_{r 1} \\
M_{r 2} \\
\vdots \\
M_{r i} \\
\vdots \\
M_{r n}
\end{array}\right]=\left[\frac{w}{6(E)_{t}}\right] \times\left[\begin{array}{cccccc}
B_{1}+C\left(H-X_{1}\right) & C\left(H-X_{2}\right) & \cdots & C\left(H-X_{i}\right) & \cdots & C\left(H-X_{n}\right) \\
C\left(H-X_{2}\right) & B_{2}+C\left(H-X_{2}\right) & \cdots & C\left(H-X_{i}\right) & \cdots & C\left(H-X_{n}\right) \\
\vdots & \vdots & \vdots & \vdots & \vdots & \vdots \\
C\left(H-X_{i}\right) & C\left(H-X_{i}\right) & \cdots & B_{i}+C\left(H-X_{i}\right) & \cdots & \vdots \\
\vdots & \vdots & \vdots & \vdots & \vdots & C\left(H-X_{n}\right) \\
C\left(H-X_{n}\right) & C\left(H-X_{n}\right) & \cdots & C\left(H-X_{n}\right) & \cdots & B_{n}+C\left(H-X_{n}\right)
\end{array}\right]^{-1}\left[\begin{array}{c}
H^{3}-X_{1}^{3} \\
H^{3}-X_{2}^{3} \\
\vdots \\
H^{3}-X_{i}^{3} \\
\vdots \\
H^{3}-X_{n}^{3}
\end{array}\right]
$$

where the parameter $B_{i}$ and $C$ are defined in the following equations.

$$
B_{i}=\frac{L}{12(E I)_{o i}} \quad C=\frac{1}{(E I)_{t}}+\frac{2}{L^{2}(E A)_{c}}
$$

where $(E I)_{o i}$ represents the equivalent bending stiffness of the $i^{\text {th }}$ outrigger wall, as given in Equation (1).

Applying the restraining moment $M_{r i}$ on the core, the displacement at the top of the building $\Delta_{t o p}$ can be obtained by using the following equation.

$$
\Delta_{\text {top }}=\frac{w H^{4}}{8(E I)_{t}}-\frac{1}{2(E I)_{t}} \sum_{i=1}^{n} M_{r i}\left(H^{2}-X_{i}^{2}\right)
$$

The outriggers are subjected to the overturning moment $M_{r i}$ and shear forces at the far edge due to the axial forces of the perimeter columns. According to the resulting rotation $\theta_{\text {oti }}$, the internal shear forces of the outrigger walls can be calculated by dividing $M_{r i}$ by $L$ as follows.

$$
\left[\begin{array}{c}
V_{1} \\
V_{2} \\
\vdots \\
V_{i} \\
\vdots \\
V_{n}
\end{array}\right]=\left[\frac{w}{6(E I)_{t}}\right] \times\left[\begin{array}{cccccc}
B_{1}+C\left(H-X_{1}\right) & C\left(H-X_{2}\right) & \cdots & C\left(H-X_{i}\right) & \cdots & C\left(H-X_{n}\right) \\
C\left(H-X_{2}\right) & B_{2}+C\left(H-X_{2}\right) & \cdots & C\left(H-X_{i}\right) & \cdots & C\left(H-X_{n}\right) \\
\vdots & \vdots & \vdots & \vdots & \vdots & \vdots \\
C\left(H-X_{i}\right) & C\left(H-X_{i}\right) & \cdots & B_{i}+C\left(H-X_{i}\right) & \cdots & \vdots \\
\vdots & \vdots & \vdots & \vdots & \vdots & C\left(H-X_{n}\right) \\
C\left(H-X_{n}\right) & C\left(H-X_{n}\right) & \cdots & C\left(H-X_{n}\right) & \cdots & B_{n}+C\left(H-X_{n}\right)
\end{array}\right]^{-1}\left[\begin{array}{c}
H^{3}-X_{1}^{3} \\
H^{3}-X_{2}^{3} \\
\vdots \\
H^{3}-X_{i}^{3} \\
\vdots \\
H^{3}-X_{n}^{3}
\end{array}\right]
$$

\subsection{Verification by Numerical Examples}

The accuracy of the proposed equations for lateral displacement at the top of tall buildings and shear forces developed at the outrigger walls are verified by comparing with the results from linear finite element analysis. MIDAS-Gen [17] was used for the linear finite element analysis because it is widely used in the structural design practice. The outrigger walls and cores were modeled with the quadrilateral plane stress elements with incompatible modes [17].

Six models were analyzed to verify the proposed equations. Models A1 A3 were the singleoutrigger structures. Model A4 and A5 were the two-outrigger structures. Model A6 included the three-outrigger structures. The overall height of the structure is $H=280 \mathrm{~m}$, with story height being equal to $3.5 \mathrm{~m}$ with 80 stories. The additional dimensional conditions are shown in Figure 4 . The uniform lateral load $w$ is applied at the center of the core wall. The floor diaphragm was neglected to assign the same boundary conditions as assumed in Equations (6) and (7). Except for the locations, all outriggers have the same dimensions and elastic modulus of $36.4 \mathrm{GPa}$. The lateral displacement at the top of the structure $\Delta_{\text {top }}$ and internal shear forces of the outrigger walls $V$ from two analysis methods are presented in Table 1. The difference shown in Table 1 is the percentage of the absolute value of the difference between the two results, which is compared to the results from the finite element method. As shown in Table 1, the differences in the top drift and shear forces between two analysis results were less than 5\%. A possible explanation for the discrepancy might be that the effective bending stiffness given in Equation (1), in which the clear distance and shear deformation are included, does not represent the actual deformation of the outrigger walls. However, these differences can be 
regarded as permitted in a structural design practice. Taken together, these results can hold the view that the proposed analytical equations for the outrigger walls that introduce the equivalent bending stiffness are valid.

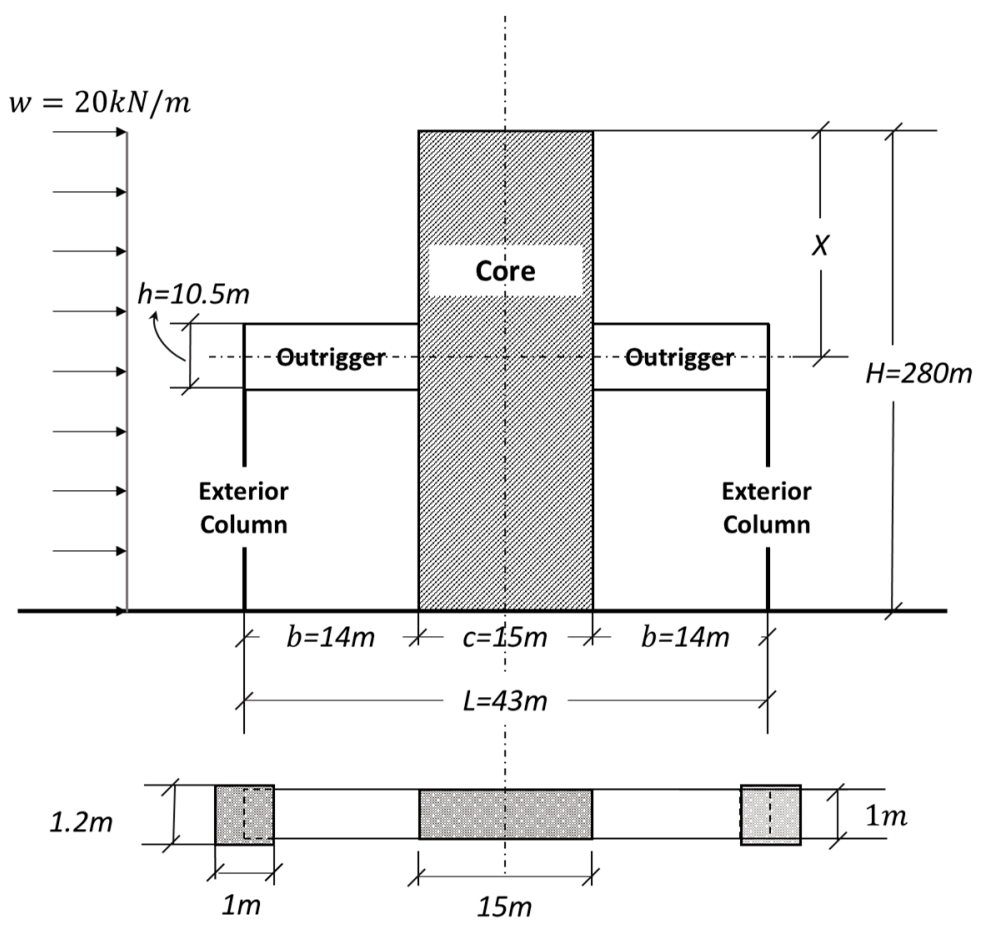

Figure 4. Dimensions of the analysis model to verify the proposed analytical equations.

Table 1. Results from Equations (6) and (7) and finite element analysis (FEA).

\begin{tabular}{|c|c|c|c|c|c|c|c|c|}
\hline \multirow{2}{*}{ Model } & \multirow{2}{*}{ Outrigger } & \multirow{2}{*}{$X(\mathrm{~m})$} & \multicolumn{2}{|c|}{$\Delta_{t o p}(\mathrm{~m})$} & \multirow{2}{*}{ Diff. (\%) } & \multicolumn{2}{|c|}{$V(\mathrm{kN})$} & \multirow{2}{*}{ Diff. (\%) } \\
\hline & & & Equation (6) & FEA & & Equation (7) & FEA & \\
\hline A1 & O11 & 89.25 & 0.4964 & 0.5134 & 3.30 & 6790 & 6876 & 1.25 \\
\hline $\mathrm{A} 2$ & $\mathrm{O} 21$ & 138.25 & 0.4715 & 0.4905 & 3.87 & 8267 & 8331 & 0.77 \\
\hline A3 & $\mathrm{O} 31$ & 183.75 & 0.5782 & 0.5985 & 3.39 & 9842 & 9840 & 0.02 \\
\hline \multirow{2}{*}{ A4 } & $\mathrm{O} 41$ & 89.25 & \multirow{2}{*}{0.3701} & \multirow{2}{*}{0.3789} & \multirow{2}{*}{2.34} & 3669 & 3808 & 3.65 \\
\hline & $\mathrm{O} 42$ & 183.75 & & & & 6273 & 6225 & 0.77 \\
\hline \multirow{2}{*}{ A5 } & O51 & 68.25 & \multirow{2}{*}{0.3831} & \multirow{2}{*}{0.3908} & \multirow{2}{*}{1.96} & 3908 & 4028 & 2.97 \\
\hline & O52 & 208.25 & & & & 6967 & 6890 & 1.11 \\
\hline \multirow{3}{*}{ A6 } & O61 & 68.25 & \multirow{3}{*}{0.3412} & \multirow{3}{*}{0.3429} & \multirow{3}{*}{0.42} & 2111 & 2220 & 4.92 \\
\hline & O62 & 138.25 & & & & 3597 & 3528 & 1.95 \\
\hline & O63 & 208.25 & & & & 5232 & 5155 & 1.51 \\
\hline
\end{tabular}

\subsection{Arrangement of Multiple Openings}

Outrigger walls behave as cantilever deep beams, which have nonlinear distribution of stresses. It is not easy to analyze and design outrigger walls through design methods and formulas developed for slender beams. In this study, the strut-and-tie model was used to perform a preliminary design of the reinforced concrete outrigger walls. The strut-and-tie model was proven to be a desirable approach for designing reinforced concrete members with discontinuous regions (D-regions). The method is based on a truss analogy, which was first presented to explain the contribution of transverse reinforcement to the shear strength of a beam by Wilhelm Ritter in 1899. Following this, Schlaich et al. [18] developed a strut-and-tie model as a design method for the D-region, and later discussed some designing details [19]. Furthermore, the strut-and-tie model method has been adopted by some design provisions, such as American Concrete Institute (ACI) 318-14 [16] as a design method for structures with D-regions. 
By using the strut-and-tie model, which assumes that all the stresses are condensed in struts and ties, horizontal and diagonal reinforcements were placed in the region with high tensile stresses. Meanwhile, in a practical situation, lateral loads coming from different directions lead to the fact that every half-side outrigger should be able to support upward and downward forces. This means that the tension zones could likely become compressive zones in an outrigger wall, and compressive zones should also be able to resist tension forces. Thus, every half-side of an outrigger wall with four reinforcements can be obtained by a symmetric superposition of the side supported upward forces and side supported downward forces, as shown in Figure 5 in which the blue lines represent steel reinforcements.

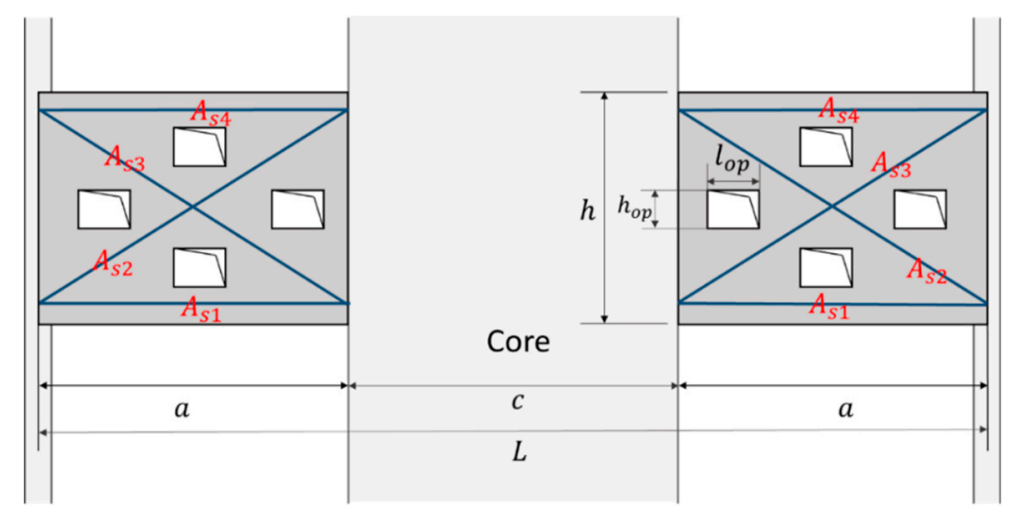

Figure 5. Outrigger walls with multiple openings. The blue lines represent the steel reinforcements to resist tension forces.

According to American Concrete Institute (ACI) 318-14, the distributed transverse reinforcement should be positioned for compressive strength of concrete $f_{c}^{\prime}$ not exceeding $42 \mathrm{MPa}(6000 \mathrm{psi})$. However, there is some difficulty in the placement of the distributed transverse reinforcement in an outrigger wall with multiple openings, which is shown in Figure 5. In this study, the compressive strength of concrete that was used in the outrigger walls was greater than $42 \mathrm{MPa}$ in order to evade the requirement for web reinforcement. Therefore, the outrigger wall was reinforced with four main reinforcements along the tension zone. The sectional area of each reinforcement was given by $A_{s 1}, A_{s 2}, A_{s 3}$, and $A_{s 4}$. These reinforcements divide the outrigger wall into four parts, as shown in Figure 6, in which the yellow colored regions were subjected to low stresses. It is essential to install openings in the regions subjected to low stresses.

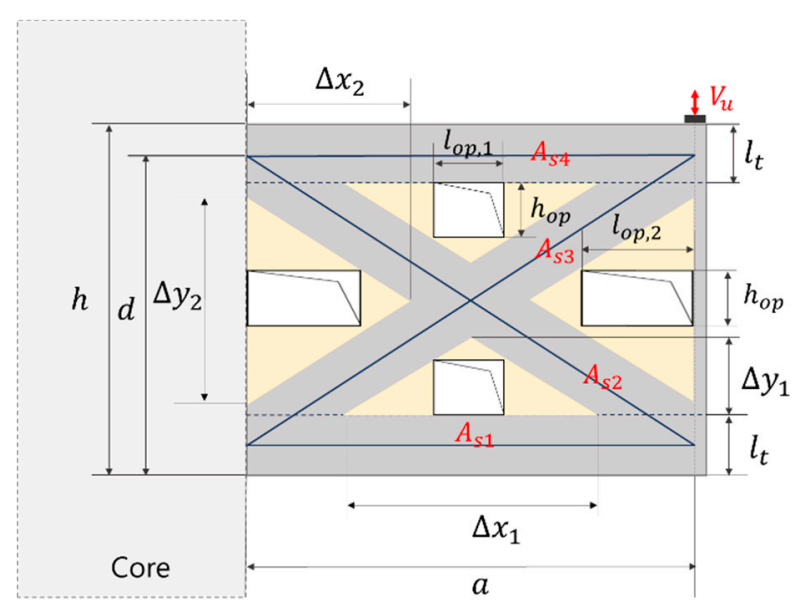

Figure 6. Arrangement of multiple openings in a reinforced concrete outrigger wall. The height of openings was assumed to be $2 \mathrm{~m}$ for it to be used as a passageway. 
Through geometrical symmetry, the right triangular region was the same as the left one with the length, $\Delta x_{2}$, and height, $\Delta y_{2}$. On the other hand, the bottom triangular region was the same as the top one with length, $\Delta x_{1}$, and height, $\Delta y_{1}$. A half-side outrigger wall has a shear span, $a$, an effective depth, $d$, and overall depth of outrigger wall, $h$, as shown in Figure 6 . The effective width of the tie, $l_{t}$, is equal to $2(h-d)$ and is also a limitation to the location of the top and bottom openings.

In order to get the maximum rectangular openings, rectangular openings should be inscribed in the triangular zones. In a practical view, the height of rectangular openings is assumed to be $2 \mathrm{~m}$ since it used to be the passageway. With the specified opening height, $h_{o p}$, the maximum length of the top and bottom openings, $l_{o p, 1}$, as well as the maximum length of the left and right openings, $l_{o p, 2}$, can be obtained by the following geometrical calculation.

$$
l_{o p, 1}=\Delta x_{1} \frac{\left(\Delta y_{1}-2\right)}{\Delta y_{1}} \quad l_{o p, 2}=\Delta x_{2} \frac{\left(\Delta y_{2}-2\right)}{\Delta y_{2}}
$$

where $\Delta x_{1}, \Delta y_{1}, \Delta x_{2}$, and $\Delta y_{2}$ are defined in Figure 6.

If the four openings are assumed to be the same size, among the length of the four openings, $l_{o p}$ is the smaller one compared to $l_{o p, 1}$ and $l_{o p, 2}$.

$$
l_{o p}=\min \left(l_{o p, 1}, l_{o p, 2}\right)
$$

The total area of openings $A_{o p}$ can also be obtained using the equation below.

$$
A_{o p}=4 l_{o p} h_{o p}
$$

\section{Evaluation of the Influence of Multiple Openings}

In order to study the influence of the size of openings on the outrigger wall and whole structure, structural performances associated with the stiffness and strength are investigated by using both linear and nonlinear analyses. Since the strength of the reinforced concrete outrigger wall cannot be evaluated by linear analysis, the strength of the outrigger wall is obtained by the nonlinear finite element analysis and compared with the results from the strut-and-tie models presented in ACI 318-14. On the other hand, the initial stiffness of the outrigger wall can be estimated by linear analysis. Therefore, the stiffness of the wall was evaluated by linear and nonlinear finite element analyses, and the results from both analyses were compared.

A single-outrigger-braced tall building with a 3-story-high outrigger system located in 39th, 40th, and 41st floor of the tall building structure shown in Figure 1 was studied as a numerical example. The overall depth, $h$, of the outrigger wall was $10.5 \mathrm{~m}$. As a symmetrical structure, only the half-side outrigger wall subjected to downward forces was analyzed. Through the proposed design procedure, the cross-sectional areas of the diagonal reinforcements $\left(A_{s 2}\right.$ and $\left.A_{s 3}\right)$ and horizontal reinforcements $\left(A_{s 1}\right.$ and $A_{s 4}$ ) were assumed to be $0.057 \mathrm{~m}^{2}$ and $0.099 \mathrm{~m}^{2}$, respectively. The outrigger wall had a shear span, $a$, of $14 \mathrm{~m}$ and an effective depth, $d$, of $10 \mathrm{~m}$. The compressive strength of concrete $f_{c}^{\prime}$ was $60 \mathrm{MPa}$.

The size of the openings was changed through 12 analyses models. The models were named by assigning a capital $\mathrm{M}$ followed by a number $i(i=0,1,2, \ldots, 11)$. Among them, model M0 refers to the outrigger wall without opening a reference model. All the openings have the specified height $\left(h_{o p}=2 \mathrm{~m}\right.$ ). Since the $250 \mathrm{~mm} \times 250 \mathrm{~mm}$ size of the rectangular element was used in the finite element mesh, the length of the opening starting from 0 increased by $0.5 \mathrm{~m}$ steps and reached their limitations in model M11. The opening ratios $\left(A_{o p} / A_{\text {out }}\right)$ are defined as the area ratios of the four openings and outrigger walls. This study aimed to find out whether and how the stiffness and the shear strength of outrigger walls change by increasing the opening ratio. In order to illustrate the influence upon the stiffness and shear strength, parameters expressing the variation are introduced. The parameter $\beta_{K}$ is the ratio of the stiffness $K_{i}$ of each outrigger wall to the stiffness $K_{0}$ of the outrigger wall without 
openings. The parameter $\beta_{V}$ is the ratio of the shear strength $V_{i}$ to the shear strength $V_{0}$ of the outrigger wall without openings.

\subsection{Finite Element Modelling}

In this study, Abaqus [20], which is a commercial nonlinear finite element analysis program, was used. Several researchers have used Abaqus in analyzing the nonlinear behavior of reinforced concrete structures [21-24]. The program provides three material models for concrete. These are the smeared crack concrete, brittle crack concrete, and concrete damaged plasticity models. In this paper, the concrete damaged plasticity (CDP) model was used because it can represent the complete inelastic behavior of concrete, both in compression and tension [25,26]. The CDP is a continuum, plasticity-based, damage model for concrete. It assumes that the main two failure mechanisms of concrete material are tensile cracking and compressive crushing, which are represented by the uniaxial tension and compression behavior. Under uniaxial tension, the stress-strain response follows a linear elastic relationship until the value of the failure stress is reached. The failure stress corresponds to the onset of micro-cracking in concrete material. Beyond the failure stress, the formation of micro-cracks is represented macroscopically with a softening stress-strain response, which induces strain localization in concrete structures. Under uniaxial compression, the response is linear up to the value of the initial yield. In the plastic regime, the response is typically characterized by stress hardening, which is followed by strain softening beyond ultimate stress.

The CDP model in Abaqus is a plasticity material model that requires the definition of the yield surface and requires hardening and flow rules. The model makes use of the yield function proposed by Lee and Fenves [27] to account for varying degrees of evolution of concrete strength under tension and compression. The CDP model assumes a non-associated potential plastic flow. The flow potential is the Drucker-Prager hyperbolic function, which requires the dilation angle $(\psi)$, flow potential eccentricity $(\epsilon)$, ratio of the initial biaxial compressive yield stress to the initial uniaxial compressive yield stress $\left(\sigma_{b 0} / \sigma_{c 0}\right)$, and the ratio of the second stress invariant on the tensile meridian to that on the compressive meridian $\left(K_{c}\right)$. The viscosity parameter should be entered to overcome some of the convergence difficulties caused by material models exhibiting softening behavior and stiffness degradation. The values of the parameters for the plasticity model used in this study are shown in Table 2 below.

Table 2. Plasticity parameter of concrete damaged plasticity (CDP) specified for this study.

\begin{tabular}{cc}
\hline Parameter & Value \\
\hline$\psi$ & 38 \\
$\epsilon$ & 0.1 \\
$\sigma_{b 0} / \sigma_{c 0}$ & 1.16 \\
$K_{c}$ & 0.667 \\
Viscosity parameter & 0.0001 \\
\hline
\end{tabular}

CDPs require a stress-strain relationship of concrete in uniaxial compression and tension. The relationship suggested by Carreira and Chu [28], as shown in Figure 7, was used for the compression model. For the tension model, the stress-strain relationship proposed by Wahalathantri et al. [29] was used. The tension model as shown in Figure 8 includes the tension stiffening to simplify the post cracking behavior for concrete and the interaction between reinforcement and concrete. The CDP model was used in predicting the shear behavior of reinforced and prestressed concrete deep beams and confirmed that the shear strengths predicted by the finite element analysis agreed well with those obtained by experiments [30]. 


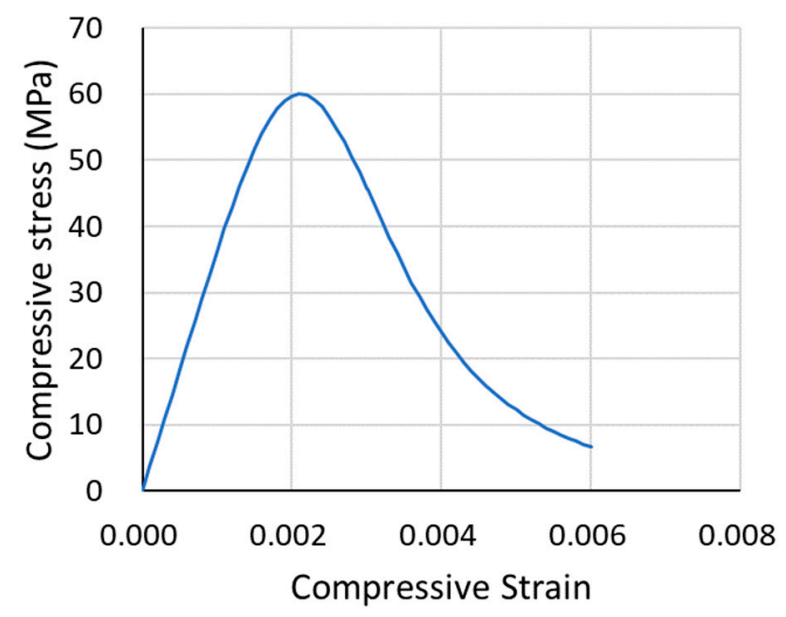

Figure 7. Compressive stress-strain relationship of concrete.

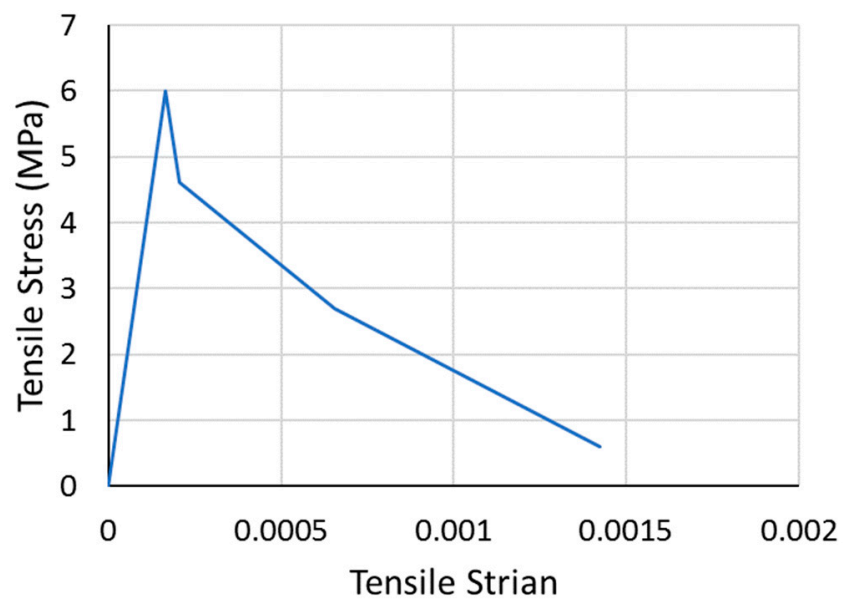

Figure 8. Compressive stress-strain relationship of concrete.

When applying downward force on the loading plate for the analysis model used in this study, the reinforcements with cross-sectional areas $A_{s 1}$ and $A_{S 3}$ were subjected to compression. On the other hand, the reinforcements with cross-sectional areas $A_{s 2}$ and $A_{s 4}$ were subjected to tensile forces. To model the behavior of stress reduction caused by buckling in a reinforcement subjected to compression, the material model was defined differently from the material model of the reinforcement subjected to tension. For the reinforcement with cross-sectional areas $A_{s 2}$ and $A_{s 4}$, which were subjected to tension, only the yield strength of $414 \mathrm{MPa}$ and modulus of elasticity of $200 \mathrm{GPa}$ were specified by assuming perfect plasticity, as shown in Figure 9. The compressive reinforcements were assumed to be buckled at a compressive strain of 0.003 and reduced the strength to $10 \%$ of the yield strength, as shown in Figure 9.

The structures used in this study were symmetrical structures. For the convenience of analysis, half of the entire outrigger wall was taken and modeled two-dimensionally. The half-side outrigger wall was modeled with half of the core wall and the loading plate at which the vertical displacement was applied. The loading plate replaced the perimeter column and was assumed to be perfectly bonded to the concrete and modeled to share the nodes with concrete. Both concrete and loading plates were modeled by using CPS4R, which is a quadrilateral plane stress element with reduced integration. The reinforcements were represented with a T2D2 truss element and were modeled by embedding them in concrete. It was assumed that the reinforcement and concrete were perfectly bonded and the interaction between two materials was indirectly represented by the tension stiffening, as shown in Figure 8. Vertical displacement was applied to the loading plate in the form of displacement control. The left, top, and bottom sides of the core wall were constrained as pinned boundary conditions. 


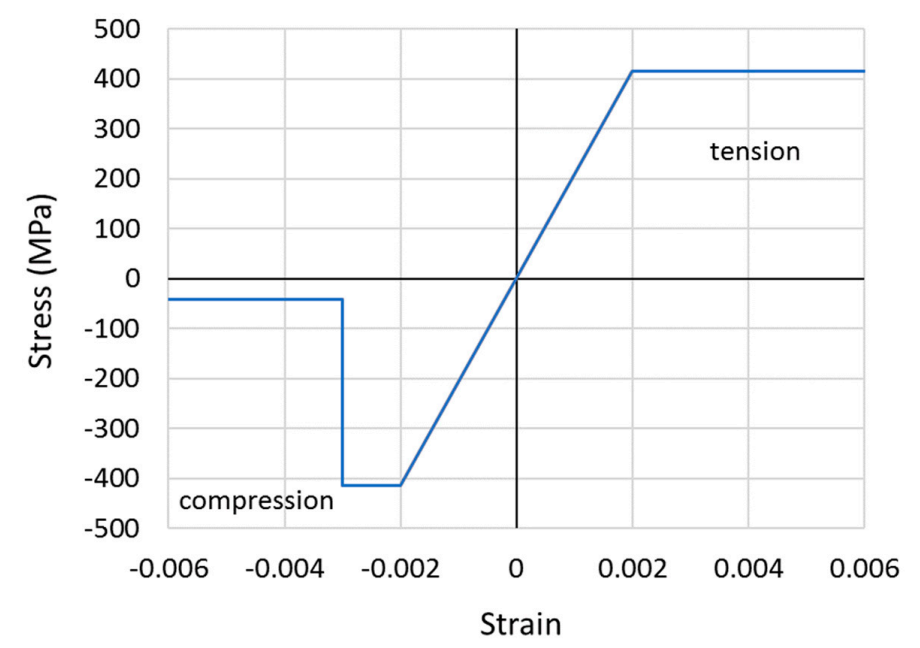

Figure 9. Material model of reinforcement subjected to tension and compression.

\subsection{Results of Finite Element Analysis}

The absolute maximum principal stress distribution calculated by the nonlinear finite element analysis is shown in Figure 10. In the outrigger wall without web openings (M0), the results show that the compressive strut was formed from the loading plate, and the bottom of the outrigger wall and tensile zone was formed at the top of the outrigger wall. In the outrigger wall with web openings (M8), compressive strut was more clearly formed at the diagonal line. Additionally, the bottom strut was formed separately from the diagonal strut. It was also observed that the cross-section of the diagonal strut was slightly defected by the openings.

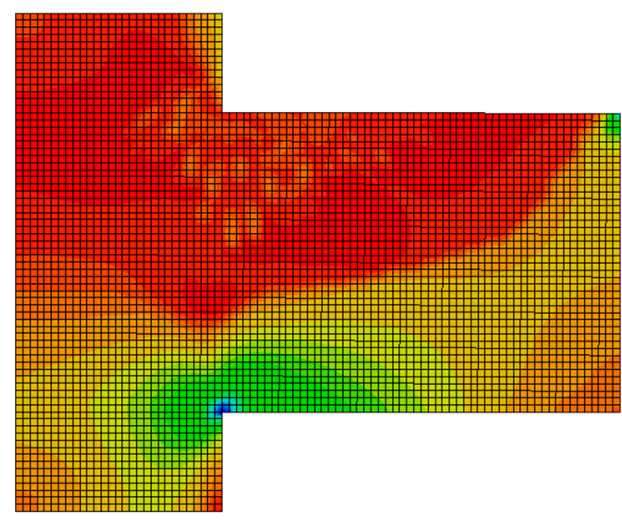

(a)

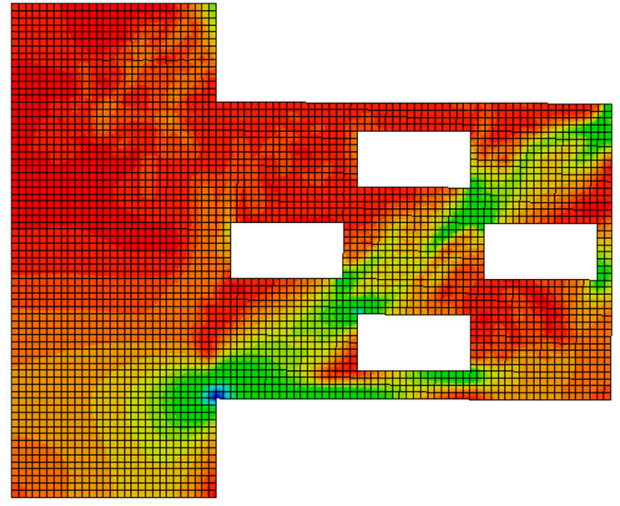

(b)

Figure 10. Absolute maximum principal stress distribution of (a) M0 and (b) M8.

The maximum plastic strain distribution at the ultimate state is shown in Figure 11. The maximum plastic strain represents the tensile strain in concrete, and the distribution shows the crack pattern of the analysis models. In the M0 model, the widest crack developed in the flexural critical section at which the outrigger wall meets the core wall. Several flexural cracks developed along the top reinforcement. The diagonal crack initiated at the loading plate and developed along the diagonal reinforcement, which was subjected to compression, was also noticeable. In model M1, many cracks developed along the top and diagonal reinforcements, which were subjected to tension. It was also noticed that wide local cracks were developed at the bottom left corner of the openings. In M8, the crack initiated at the loading plate and propagated along the top reinforcement, which formed a large arc along the corners of openings. In M11, in which the compressive struts interfered by the openings, the ultimate state developed by the local failure at the corners of the top and right openings. 


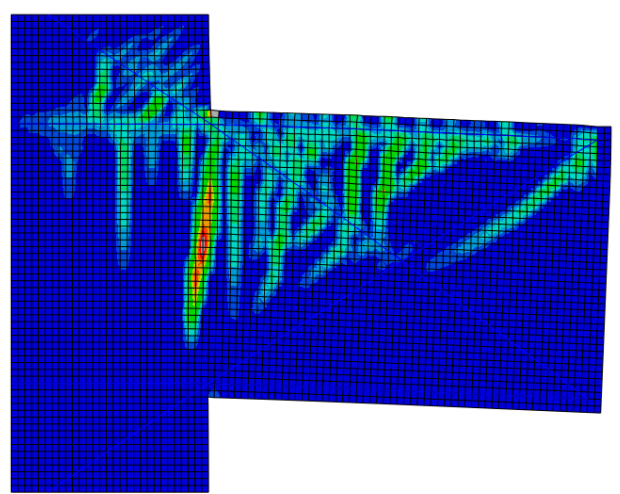

(a)

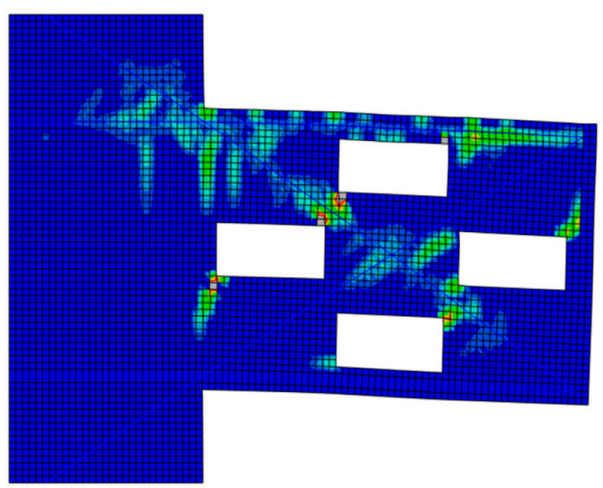

(c)

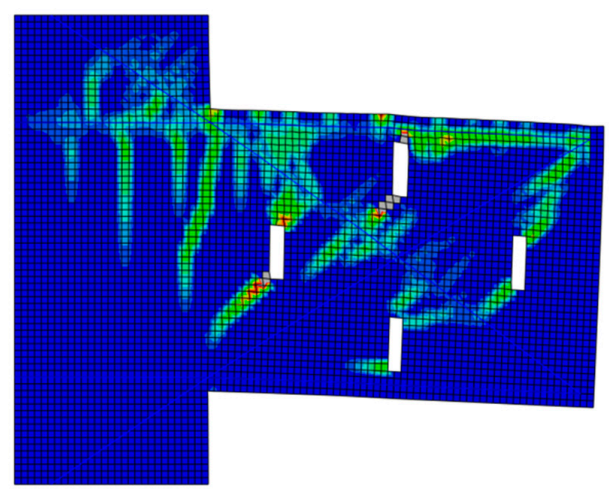

(b)

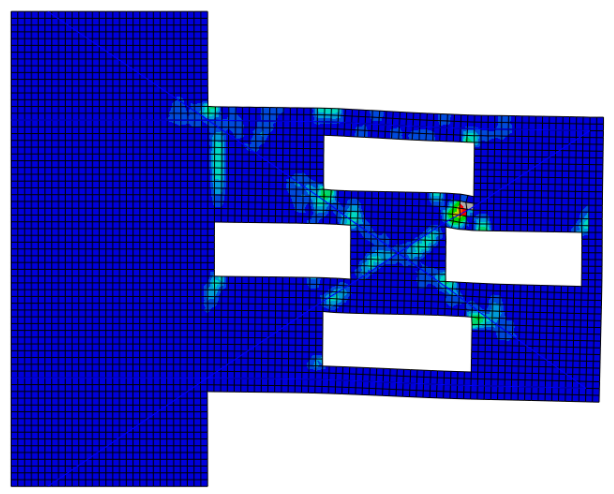

(d)

Figure 11. Plastic strain distribution at the ultimate state of (a) M0, (b) M1, (c) M8, and (d) M11.

Figure 12 shows the relation between the applied vertical displacement and total vertical reactions measured at the pinned nodes from the nonlinear analysis. It can be clearly observed that the outrigger walls experienced a progressive decrease in both stiffness and strength as the size of the opening increased. However, the ultimate displacement of all the models, except M11, were around $60 \mathrm{~mm}$ and the initial yielding was developed at about $10 \mathrm{~mm}$.

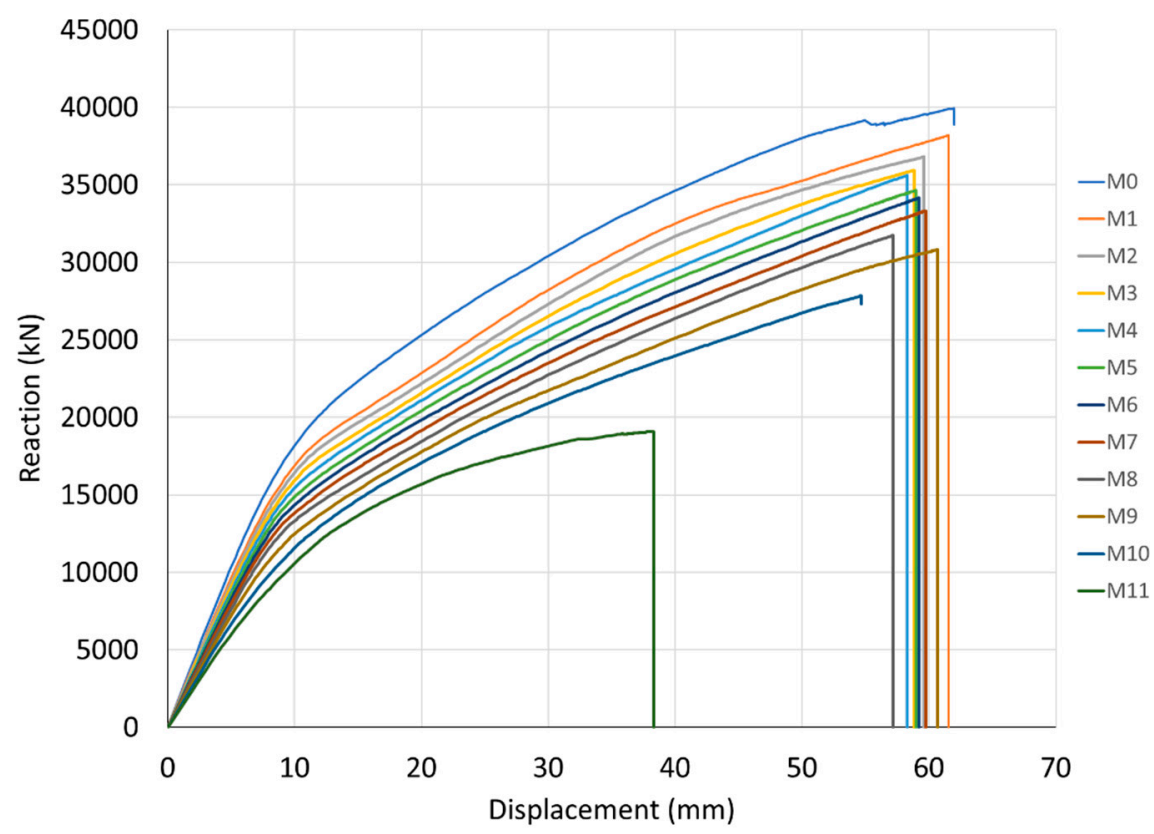

Figure 12. Displacement-reaction curves of nonlinear analysis. 
In order to quantify the degradation in stiffness due to the size of openings, the initial tangential slope, $K_{t i}$, calculated from the load-displacement curves shown in Figure 12 and compared it with the slope $K_{i}$ from the linear analysis. In order to evaluate the stiffness of outrigger walls, all the analysis models were constructed as the same as the nonlinear analysis, with an exception of the plastic modeling removed in the linear analysis. The slope of the linear analysis $K_{i}$ is defined as the vertical force developing a unit deflection at the loading point of the $i$-th model in the linear analysis. The term $K$ can be defined as the tangential stiffness of the outrigger walls. The initial tangential slopes $K_{t i}$ from the nonlinear analysis and stiffness $K_{i}$ from the linear analysis were identical.

To include the effect of initial cracking in the nonlinear analysis, the secant stiffness, $K_{s i}$, were defined as the slope from the origin to the point with vertical displacement of $10 \mathrm{~mm}$ and are shown in Table 3 with the stiffness $K_{i}$ from the linear analysis. As mentioned before, $\beta_{K}$ is defined as the ratio of $K_{i}$ to $K_{0}$ or $K_{s i}$ to $K_{s 0}$ of the outrigger wall without openings. $\beta_{K}$ is regarded as an index to show the degradation of stiffness of the outrigger walls. It can be observed that, even though the secant stiffness was slightly less than the tangential stiffness, $K_{i}$ and the degradation ratio $\beta_{K}$ were almost identical.

Table 3. Evaluation of stiffness of the outrigger wall.

\begin{tabular}{cccccc}
\hline \multirow{2}{*}{ Model } & \multirow{2}{*}{$\boldsymbol{A}_{\text {op }} / \boldsymbol{A}_{\text {out }}$} & \multicolumn{2}{c}{ Linear Analysis } & \multicolumn{2}{c}{ Nonlinear Analysis } \\
\cline { 3 - 5 } & & $\boldsymbol{K}_{\boldsymbol{i}} \mathbf{( M N )}$ & $\boldsymbol{\beta}_{\boldsymbol{K}}$ & $\boldsymbol{K}_{\boldsymbol{s i}}(\mathbf{M N})$ & $\boldsymbol{\beta}_{\boldsymbol{K}}$ \\
\hline M0 & 0.00 & 2124 & 1.00 & 1817 & 1.00 \\
M1 & 0.03 & 1973 & 0.93 & 1690 & 0.93 \\
M2 & 0.05 & 1914 & 0.90 & 1642 & 0.90 \\
M3 & 0.08 & 1858 & 0.87 & 1593 & 0.88 \\
M4 & 0.11 & 1801 & 0.85 & 1542 & 0.85 \\
M5 & 0.14 & 1742 & 0.82 & 1487 & 0.82 \\
M6 & 0.16 & 1685 & 0.79 & 1435 & 0.79 \\
M7 & 0.19 & 1625 & 0.76 & 1383 & 0.76 \\
M8 & 0.22 & 1557 & 0.73 & 1332 & 0.73 \\
M9 & 0.24 & 1468 & 0.69 & 1248 & 0.69 \\
M10 & 0.27 & 1365 & 0.64 & 1156 & 0.64 \\
M11 & 0.29 & 1234 & 0.58 & 1056 & 0.58 \\
\hline
\end{tabular}

Figure 13 shows the degradation ratios in stiffness as the size of the opening increases. The ratios of the stiffness decline almost linearly with a gentle slope from M0 to M8. When the opening area exceeds $22 \%$ (M8), the decreasing trends are also regarded as being linear, but they become steeper. From the similar trends in the results of linear and nonlinear analyses, it can be concluded that the loss of area due to multiple openings is a more influential factor on the stiffness of outrigger walls than the material degradation.

The maximum vertical reaction, $R_{i}$, in the nonlinear analysis can be defined as the strength of the outrigger walls. The ratio $\beta_{R}$ refers to the ratio of the vertical reaction at the ultimate state of the $i$-th models $R_{i}$ to $R_{0}$ of the M0 model. The maximum vertical reactions and degradation ratio in strength from the nonlinear analysis are shown in Table 4 and Figure 14. The reduction in strength is a function of the opening ratio, which is similar to the results of stiffness. However, the outrigger wall began to experience larger losses in strength when the opening area reached $24 \%$ (M9) in which the shear strength reduced to $77 \%$. Comparing the reduction of stiffness and strength in model M0 to model M8, where the sizes of openings were less than $22 \%$ of the overall area of the outrigger wall, the gentle reductions in stiffness and strength were similar, while the sharp reduction occurred earlier in the stiffness (M8) than in strength (M9). 


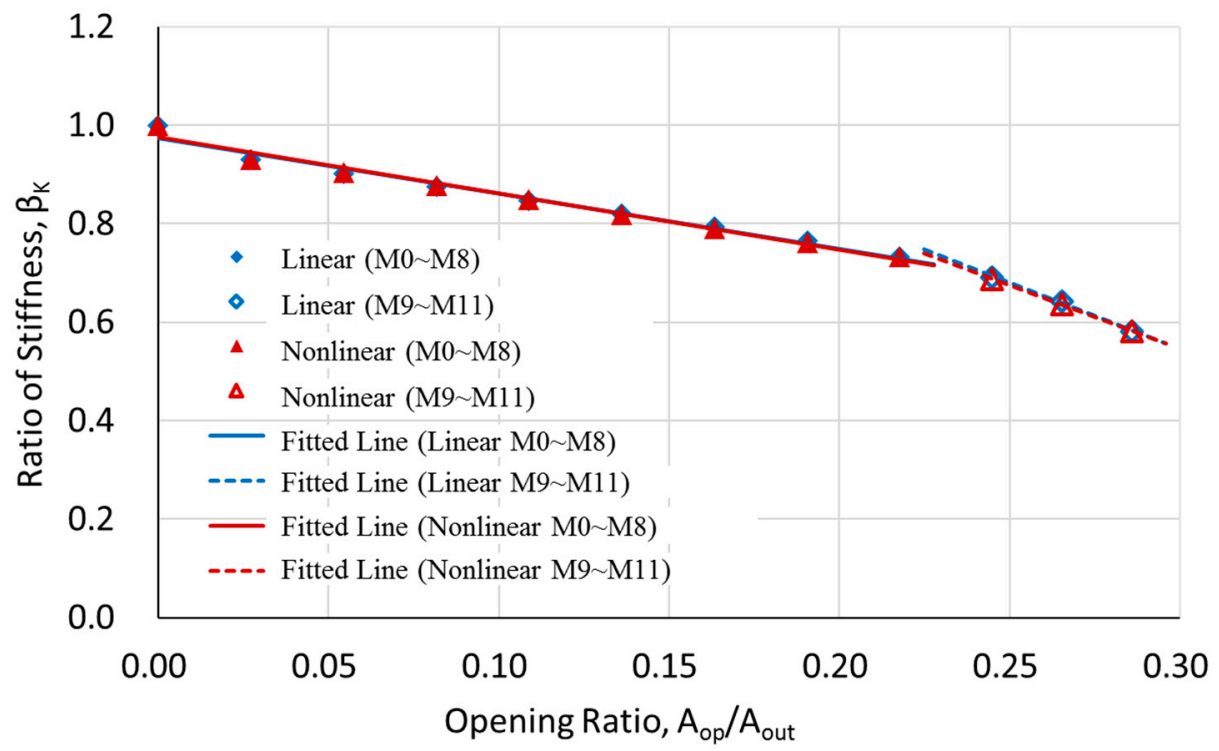

Figure 13. Degradation of stiffness of the outrigger wall according to the size of openings.

Table 4. Evaluation of strength of the outrigger wall.

\begin{tabular}{cccc}
\hline \multirow{2}{*}{ Model } & \multirow{2}{*}{$\boldsymbol{A}_{\text {op }} / \boldsymbol{A}_{\text {out }}$} & \multicolumn{2}{c}{ Nonlinear Analysis } \\
\cline { 3 - 4 } & & $\boldsymbol{R}_{\boldsymbol{i}} \mathbf{( k N )}$ & $\boldsymbol{\beta}_{\boldsymbol{R}}$ \\
\hline M0 & 0.00 & 39,932 & 1.00 \\
M1 & 0.03 & 38,193 & 0.96 \\
M2 & 0.05 & 36,798 & 0.92 \\
M3 & 0.08 & 35,938 & 0.90 \\
M4 & 0.11 & 35,604 & 0.89 \\
M5 & 0.14 & 34,635 & 0.87 \\
M6 & 0.16 & 34,150 & 0.86 \\
M7 & 0.19 & 33,314 & 0.83 \\
M8 & 0.22 & 31,729 & 0.79 \\
M9 & 0.24 & 30,815 & 0.77 \\
M10 & 0.27 & 27,853 & 0.70 \\
M11 & 0.29 & 19,083 & 0.48 \\
\hline
\end{tabular}

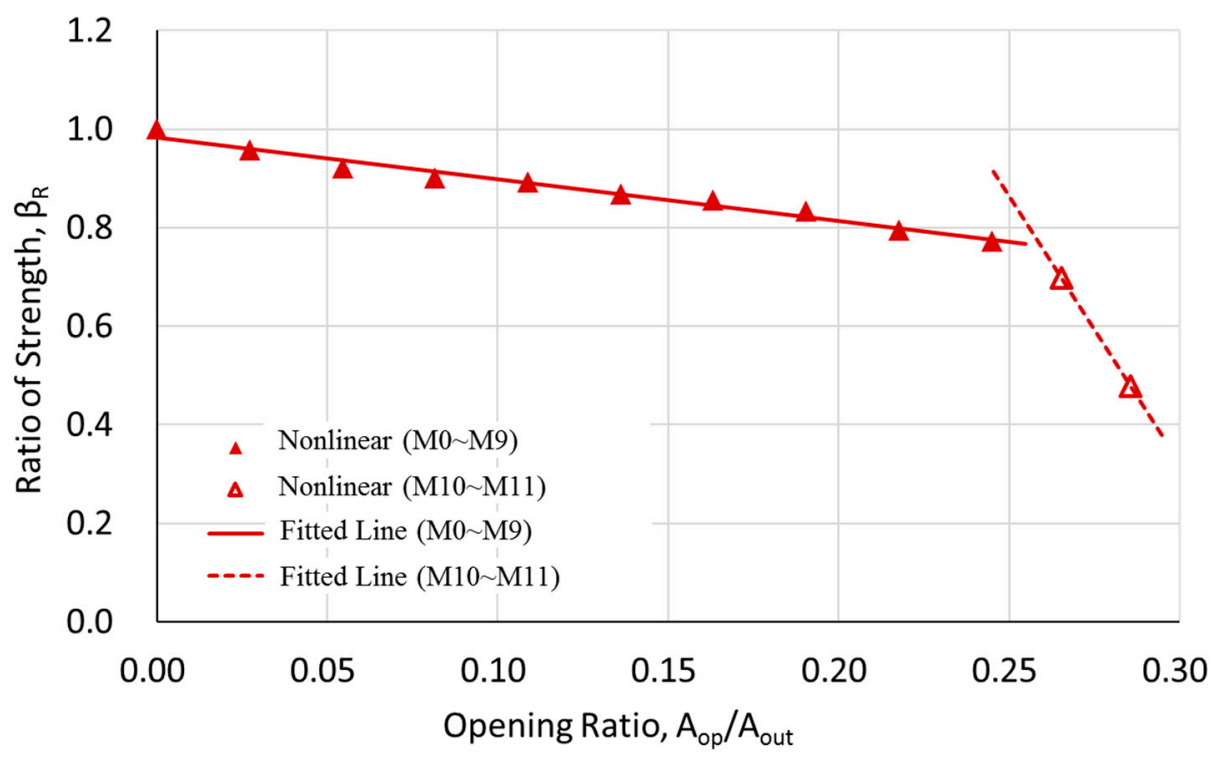

Figure 14. Degradation of strength of the outrigger wall according to the size of the openings. 
From the analysis results, it can be concluded that the reinforced concrete outrigger walls can accommodate four openings without significantly decreasing the stiffness and strength of the outrigger walls if the openings do not severely interfere with the critical load path.

\subsection{Strength Predicted by Strut-and-Tie Models}

According to Chapter 23 of ACI318-14, the nominal shear strength of the outrigger walls can be calculated by using the strut-and-tie model. In this study, the nodal zones are assumed to be stiff enough. Therefore, only the strengths of strut and tie were considered. The diagonal strut in the central zone surrounded by four openings has an angle $\theta$ with the horizontal tie, as shown in Figure 15.

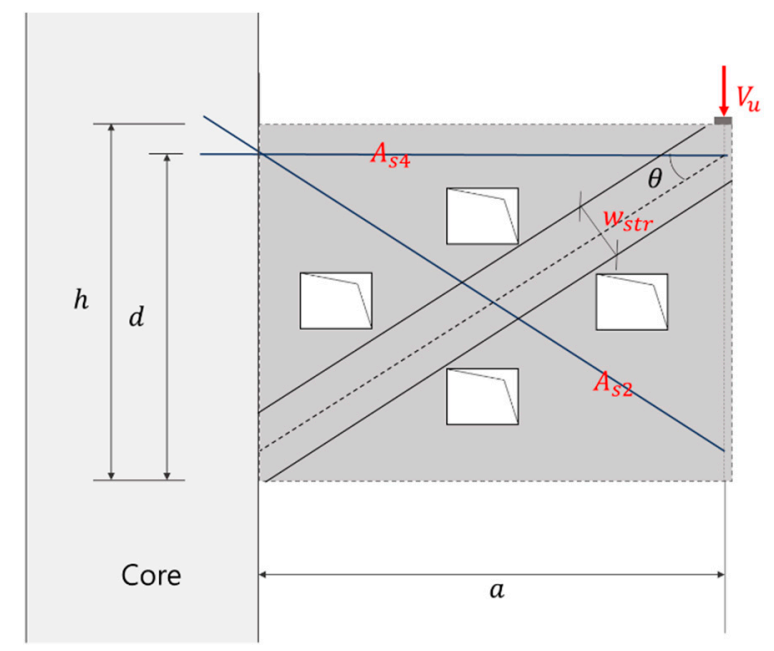

Figure 15. The strut-and-tie model for the outrigger wall with multiple openings.

The shear strength of the outrigger wall by the strut-and-tie model $V_{\text {stm }}$ was the smaller one of the shear strengths provided by the strut and the tie, as shown by the following equations.

$$
\begin{gathered}
V_{n}=F_{n s} \sin \theta \leq 0.85 \beta_{s} f_{c}^{\prime} b_{w} w_{s t r} \\
V_{n}=F_{n+2} \sin \theta+F_{n+4} \tan \theta \leq A_{s 2} f_{y} \sin \theta+A_{s 4} f_{y} \tan \theta
\end{gathered}
$$

where $F_{n s}$ is the nominal compressive strength of a strut. $\beta_{s}$ is the reduction factor to account for the bottle-shaped strut. For a strut of a uniform cross-sectional area, $\beta_{s}=1.0$ and $w_{s t r}$ is the width of strut. $F_{n t 2}$ and $F_{n t 4}$ are the nominal tensile strengths of the top and diagonal reinforcements, respectively.

The indices representing the relative strength degradation $\beta_{V}$ as increasing the size of the openings are presented in Figure 16. It can be observed that the $\beta_{V}$ remained 1.0 before the opening ratio reached $19 \%$ (M0-M7). This means that the steel reinforcements yielded before the failure of concrete until the size of the openings reached $19 \%$. When the size of the openings increased beyond $19 \%$, the openings reduced the width of the strut and, consequently, reduced the strength of the strut and strength of the outrigger walls. The strength ratio $\beta_{V}$ began decreasing sharply from model M8 and dropped to $39 \%$ in model M11. These results indicate that the failure of concrete preceded the yielding of reinforcements in model M11. When comparing Figure 14 from the nonlinear finite element analysis and Figure 16 from the strut-and-tie model, it can be noticed that the strut-and-tie model is not conservative in predicting the shear strength of outrigger walls with low opening ratios.

\subsection{Influence on Lateral Stiffness of Tall Buildings}

The influence of openings on the stiffness and strength of reinforced concrete outrigger walls was investigated in the previous sections. In this section, the influence of openings on the lateral stiffness of the whole structure was investigated by applying the degraded stiffness of outrigger walls due to 
openings given in Table 3 to the proposed, analytical Equations (6) and (7). The equivalent bending stiffness of the outrigger wall without openings given in Equation (1) can be easily converted to the equivalent bending stiffness of the outrigger wall with openings, as shown by the following equation.

$$
(E I)_{o i}=\beta_{K}(E I)_{o}
$$

where $(E I)_{o i}$ is the equivalent bending stiffness of the $i$-th analysis models.

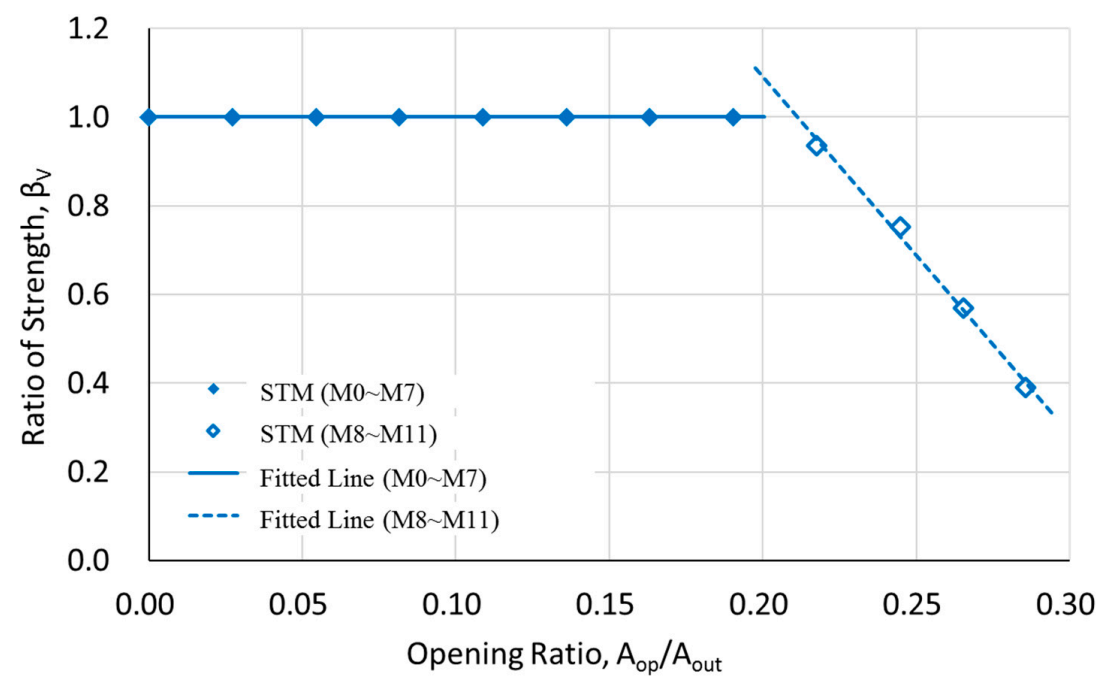

Figure 16. Strength of outrigger walls predicted by the strut-and-tie model.

The lateral displacement at the top of the building and shear forces developed in each outrigger are summarized in Table 5. The lateral displacement and shear forces were almost the same, even though the minimum value of $\beta_{K}=0.58$ (M11) was applied. According to a study by Kim [31], the relation between the lateral displacement at the top and stiffness of the outrigger is nonlinear. Moreover, the lateral displacement is not sensitive to the stiffness of the outrigger when the outrigger has sufficiently high stiffness, such as the outrigger walls in this study. Even though the internal shear force developed in each outrigger remained almost the same as seen in Table 5, the strength of the outrigger wall with openings was reduced significantly, as seen in Table 4, since the size of the openings increased. Therefore, the structural safety in terms of strength should be carefully checked when designing the reinforced concrete outrigger walls.

Table 5. The lateral displacement at the top of the building and shear forces developed in the outrigger walls predicted by Equations (6) and (7).

\begin{tabular}{|c|c|c|c|c|c|c|c|}
\hline \multirow{2}{*}{ Model } & \multirow{2}{*}{ Outrigger } & \multicolumn{2}{|c|}{$\Delta_{\text {top }}(\mathrm{m})$} & \multirow{2}{*}{ Diff. (\%) } & \multicolumn{2}{|c|}{$V(\mathbf{k N})$} & \multirow{2}{*}{ Diff. (\%) } \\
\hline & & M0 & M11 & & Mo & M11 & \\
\hline A1 & O11 & 0.4964 & 0.5050 & 1.73 & 6790 & 6732 & 0.85 \\
\hline $\mathrm{A} 2$ & $\mathrm{O} 21$ & 0.4715 & 0.4833 & 2.50 & 8267 & 8173 & 1.14 \\
\hline A3 & O31 & 0.5782 & 0.5935 & 2.65 & 9842 & 9679 & 1.66 \\
\hline \multirow{2}{*}{$\mathrm{A} 4$} & O41 & \multirow{2}{*}{0.3701} & \multirow{2}{*}{0.3777} & \multirow{2}{*}{2.01} & 3669 & 3707 & 1.04 \\
\hline & $\mathrm{O} 42$ & & & & 6273 & 6133 & 2.23 \\
\hline \multirow{2}{*}{ A5 } & O51 & \multirow{2}{*}{0.3831} & \multirow{2}{*}{0.3918} & \multirow{2}{*}{2.22} & 3908 & 3938 & 0.77 \\
\hline & O52 & & & & 6967 & 6786 & 2.60 \\
\hline \multirow{3}{*}{ A6 } & O61 & \multirow{3}{*}{0.3412} & \multirow{3}{*}{0.3470} & \multirow{3}{*}{1.70} & 2111 & 2144 & 1.56 \\
\hline & O62 & & & & 3597 & 3594 & 0.08 \\
\hline & O63 & & & & 5232 & 5089 & 2.73 \\
\hline
\end{tabular}




\section{Conclusions}

After studying outrigger systems, designing multiple openings on outrigger walls and evaluating the influence of the size of openings on outrigger walls, several conclusions can be summarized as follows.

The introduction of equivalent bending stiffness allows for the derivation of internal shear forces on the outriggers. The proposed equations include the effect of clear span and shear deformation of outrigger walls. In comparison with the results from the numerical analysis, the errors between the results of developed equations and results of finite element analysis were less than $5 \%$. This proves that the shear reaction on outrigger walls due to lateral loads derived from a simplified model can be used for the preliminary design of outrigger walls.

To use the space occupied by the outrigger walls more efficiently, a development of an outrigger wall with four reinforcements and four openings was proposed through the strut-and-tie model. The stiffness and strength of outrigger walls experience reductions in different levels since the size of openings increases. The decrease in trends can be represented by two linear functions of the opening ratios, which are the gentle and steep linear functions. The linear finite element analysis can replace the time-consuming nonlinear finite element analysis when evaluating the stiffness degradation of outrigger walls with multiple openings. Taking into consideration the degradation in stiffness and strength, the ratio of the opening area is recommended to be less than $20 \%$. The degradation of stiffness due to openings does not significantly affect the global behavior of the whole structure when the outrigger already has a large stiffness, as the case of reinforced concrete outrigger walls.

Author Contributions: Conceptualization, methodology, validation, writing-review and editing, supervision, H.-S.K. Formal analysis, data curation, writing—original draft preparation, Y.-T.H. Formal analysis, investigation, H.-J.J.

Funding: This work was supported by Konkuk University in 2017.

Conflicts of Interest: The authors declared no conflict of interest.

\section{References}

1. Choi, H.S.; Joseph, L. Outrigger system design considerations. Int. J. High-Rise Build. 2012, 1, $237-246$.

2. Ali, M.M.; Moon, K.S. Structural developments in tall buildings: Current trends and future prospects. Archit. Sci. Rev. 2007, 50, 205-223. [CrossRef]

3. Taranath, B.S. Optimum belt truss location for high-rise structures. Struct. Eng. 1975, 53, 18-21.

4. McNabb, J.W.; Muvdi, B.B. Drift reduction factors for belt high-rise structures. Eng. J. AISC 1975, $12,88-91$.

5. Smith, B.S.; Nwaka, I.O. The behaviour of multi-outrigger braced tall buildings. ACI SP-63 1980, 515-541.

6. Smith, B.S.; Salim, I. Parameter study of outrigger-braced tall building structures. J. Str. Div. ASCE 1981, 107, 2001-2014.

7. Hoenderkamp, J.C.D.; Bakker, M.C.M. Analysis of high-rise braced frames with outriggers. Struct. Des. Tall Spec. Build. 2003, 12, 335-350. [CrossRef]

8. Wu, J.R.; Li, Q.S. Structural performance of multi-outrigger-braced tall buildings. Struct. Des. Tall Spec. Build. 2003, 12, 155-176. [CrossRef]

9. Kim, H.S.; Lee, H.L.; Lim, Y.J. Multi-objective optimization of dual-purpose outriggers in tall buildings to reduce lateral displacement and differential axial shortening. Eng. Struct. 2019, 189, 296-308. [CrossRef]

10. Wang, A. Multi-dimensional hybrid design and construction of skyscraper cluster-innovative engineering of Raffles City. Int. J. High-Rise Build. 2017, 6, 261-269. [CrossRef]

11. Ho, G.W.M. The evolution of outrigger system in tall buildings. Int. J. High-Rise Build. 2016, 5, 21-30. [CrossRef]

12. Kong, F.K.; Sharp, G.R. Structural idealization for deep beams with web openings. Mag. Concr. Res. 1977, 29, 81-91. [CrossRef]

13. Tan, K.H.; Tong, K.; Tang, C.Y. Consistent strut-and-tie modeling of deep beams with web openings. Mag. Concr. Res. 2003, 55, 65-75. [CrossRef] 
14. Tang, C.Y.; Tan, K.H. Interactive mechanical model for shear strength of deep beams. J. Struct. Eng. 2004, 130, 1534-1544. [CrossRef]

15. Smith, B.S.; Coull, A. Tall Building Structures: Analysis and Design; John Wiley \& Sons: New York, NY, USA, 1991.

16. ACI Committee 318. Building Code Requirements for Structural Concrete (ACI 318-14) and Commentary (318R-14); American Concrete Institute: Farmington Hills, MI, USA, 2014.

17. Midas-Gen On-Line Manual; MIDAS Information Technology Co. Ltd. Available online: http://manual. midasuser.com/EN_Common/Gen/855/whnjs.htm. (accessed on 10 September 2019).

18. Schlaich, J.; Schäfer, K.; Jennewein, M. Towards a consistent design of structural concrete. PCI J. 1987, 32, 74-150. [CrossRef]

19. Schlaich, J.; Schäfer, K. Design and detailing of structural concrete using strut-and-tie models. Struct. Eng. 1991, 69, 113-125.

20. Abaqus. Abaqus Analysis User's Guide; Dassault Systems Simulia Corp. Available online: http://130.149.89.49: 2080/v2016/books/usb/default.htm, (accessed on 10 September 2019).

21. Wosatko, A.; Pamin, J.; Polak, M.A. Application of damage-plasticity models in finite element analysis of punching shear. Comput. Struct. 2015, 151, 73-85. [CrossRef]

22. Tao, Y.; Chen, J.F. Concrete damage plasticity model for modeling FRP-to-concrete bond behavior. J. Compos. Const. 2015, 19. [CrossRef]

23. Mohamed, K.; Farghaly, A.S.; Benmokrane, B.; Neale, K.W. Nonlinear finite-element analysis for the behavior prediction and strut efficiency factor of GFRP-reinforced concrete deep beams. Eng. Struct. 2017, 137, 145-161. [CrossRef]

24. Genikomsou, A.S.; Polak, M.A. Finite element analysis of punching shear of concrete slabs using damaged plasticity model in ABAQUS. Eng. Struct. 2015, 98, 38-48. [CrossRef]

25. Ombres, L.; Verre, S. Flexural strengthening of RC beams with steel-reinforced grout: Experimental and numerical investigation. J. Compos. Const. 2019, 23. [CrossRef]

26. Fortunato, G.; Funari, M.F.; Lonetti, P. Survey and seismic vulnerability assessment of the Baptistery of San Giovanni in Tumba (Italy). J. Cult. Herit. 2017, 26, 64-78. [CrossRef]

27. Lee, J.; Fenves, G.L. Plastic-damage model for cyclic loading of concrete structures. J. Eng. Mech. 1998, 124, 892-900. [CrossRef]

28. Carreira, D.J.; Chu, K.H. Stress-strain relationship for plain concrete in compression. ACI Struct. J. 1985, 82, 797-804.

29. Wahalathantri, B.L.; Thambiratnam, D.P.; Chan, T.H.T.; Fawzia, S. A material model for flexural crack simulation in reinforced concrete elements using Abaqus. In Proceedings of the First International Conference on Engineering, Designing and Developing the Built Environment for Sustainable Wellbeing, Brisbane, Australia, 28 April 2011; pp. 260-264.

30. Kim, H.J.; Kim, H.S. Finite element analysis to determine shear behavior of prestressed concrete deep beams. J. Comput. Struct. Eng. Inst. Korea 2019, 32, 165-172. [CrossRef]

31. Kim, H.S. Optimum design of outriggers in a tall building by alternating nonlinear programming. Eng. Struct. 2017, 150, 91-97. [CrossRef]

(C) 2019 by the authors. Licensee MDPI, Basel, Switzerland. This article is an open access article distributed under the terms and conditions of the Creative Commons Attribution (CC BY) license (http://creativecommons.org/licenses/by/4.0/). 